\title{
Relações afetivas íntimas de jovens universitários: narrativas de estudantes de enfermagem
}

\author{
Young university students' intimate affective relationships: nursing students' narratives \\ Relaciones afectivas íntimas de jóvenes estudiantes universitarios: relatos de estudiantes de enfermería
}

\author{
Aline Vieira Simões'; Lucia Helena Garcia Penna"; Vanda Palmarella Rodrigues'II, Joana labrudi Carinhanha" \\ Adriana Lenho de Figueiredo Pereira ${ }^{v}$, Juliana Costa Machado ${ }^{V I}$
}

\begin{abstract}
RESUMO
Objetivo: analisar as relações afetivas íntimas de jovens universitários do Curso de Graduação em Enfermagem de uma universidade pública, considerando a perspectiva de gênero. Método: pesquisa qualitativa baseada na narrativa de vida como referencial teórico-metodológico. Realizada entrevista individual aberta com 30 estudantes de enfermagem, no período de maio a setembro de 2017. O projeto foi aprovado por Comitê de Ética em Pesquisa. Resultados: os relacionamentos afetivos dos jovens universitários se caracterizaram pelo controle, ciúme e dominação masculina. Os jovens estudantes do curso de enfermagem se encontram expostos à vivência de distintas manifestações de violência nas relações afetivas íntimas. Eles têm nas questões de gênero a principal influência na ocorrência das violências. Conclusão: considerando o papel das universidades e sua importância na transformação da realidade social e na qualidade de vida, e ainda na formação em saúde, destaca-se a urgência do desenvolvimento de ações preventivas e de promoção de relacionamentos saudáveis entre jovens universitários. Descritores: Estudantes de enfermagem; educação superior; jovens; privacidade.
\end{abstract}

\section{ABSTRACT}

Objectives: to examine the intimate affective relationships of young university students on the undergraduate nursing course at a public university, from a gender perspective. Method: this qualitative study was based on life narrative as its theoretical and methodological framework. From May to September 2017, 30 nursing students underwent individual unscripted interviews. The project was approved by the research ethics committee. Results: the young university students' affective relationships were characterized by control, jealousy, and male domination. The young nursing students were exposed to experiencing various different manifestations of violence in their intimate affective relationships. They considered gender issues to be the main influence in the occurrence of violence. Conclusion: considering the role of universities and their importance in changing social realities and in quality of life, as well as in health education, there is an urgent need to take preventive action and to develop measures to promote healthy relationships among young university students.

Descriptors: Nursing students; higher education; young adult; privacy.

\section{RESUMEN}

Objetivos: analizar las relaciones afectivas íntimas de jóvenes estudiantes universitarios del Curso de Pregrado en Enfermería de una universidad pública, considerando la perspectiva de género. Método: investigación cualitativa basada en la narración de vida como marco teórico-metodológico. Se realizó una entrevista individual abierta junto a 30 estudiantes de enfermería, en el periodo de mayo a septiembre 2017. El Comité de Ética en Investigación aprobó el proyecto. Resultados: las relaciones afectivas de los jóvenes estudiantes universitarios se caracterizaron por el control, los celos y la dominación masculina. Los jóvenes estudiantes del pregrado en enfermería se encuentran expuestos a la experiencia de diferentes manifestaciones de violencia en sus relaciones afectivas íntimas. Las cuestiones de género son la principal influencia para las violencias. Conclusión: considerando el papel de las universidades y su importancia en la transformación de la realidad social y en la calidad de vida, y también en la educación en salud, se destaca la urgencia de desarrollar acciones preventivas y promover relaciones saludables entre jóvenes estudiantes universitarios.

Descriptores: Estudiantes de enfermería; educación superior; joven; privacidad.

\section{INTRODUÇÃO}

A juventude é uma fase da vida que envolve a elaboração de variados contextos sociais, históricos e culturais. 0 jovem precisa ser percebido nas relações e diversas formas de vivenciar as experiências sem desconsiderá-lo como membro de uma geração peculiar que se relaciona com gerações distintas ${ }^{1}$.

\footnotetext{
'Enfermeira. Mestre. Aluna do Curso de Doutorado em Enfermagem. Universidade do Estado do Rio de Janeiro. Brasil. E-mail: avsimoes@uesb.edu.br "Enfermeira. Doutora. Professora Adjunta, Universidade do Estado do Rio de Janeiro. Brasil. E-mail: luciapenna@terra.com.br I'Enfermeira. Doutora. Professora Adjunta, Universidade Estadual do Sudoeste da Bahia. Brasil. E-mail: vprodrigues@uesb.edu.br IVEnfermeira. Doutora. Professora Adjunta, Universidade do Estado do Rio de Janeiro. Brasil. E-mail: iabrudi@yahoo.com

vEnfermeira. Doutora. Professora Adjunta, Universidade do Estado do Rio de Janeiro. Brasil. E-mail: adrianalenho.uerj@gmail.com VIEnfermeira. Mestre. Aluna do Curso de Doutorado. Universidade Estadual do Sudoeste da Bahia. Brasil. E-mail: julicmachado@hotmail.com
} 
A violência nas relações afetivas íntimas entre os jovens universitários é um problema grave e de proporções devastadoras. Apresenta alta prevalência, com variação entre $20 \%$ a $30 \%$, para agressão física e sexual, e $70 \%$ a $90 \%$ para agressão psicológica ${ }^{2,3}$.

Conhecer como o fenômeno estaria presente na vida do jovem é de extrema urgência, devendo ser problematizado entre os estudantes universitários, pois o espaço acadêmico se destaca também por ser meio propulsor de discussões que embasam não apenas temas técnico-científicos de determinada profissão, mas a formação cidadã, que engloba a relação entre políticas públicas e demandas sociais.

Estabeleceu-se como objetivo deste estudo analisar as relações afetivas íntimas de jovens universitários do Curso de Enfermagem de uma universidade pública, considerando a perspectiva de gênero.

\section{REVISÃO DE LITERATURA}

No período da juventude inicia-se o processo de socialização além da família. Momento de decisões, especialmente na educação e trabalho. O jovem começa a se preparar para a futura carreira profissional em busca da estabilidade socioeconômica. Nesse período, se estabelecem, igualmente, as relações afetivas íntimas, caracterizadas pelo envolvimento íntimo entre os indivíduos, independentemente da orientação sexual, em contexto de aprendizado e descoberta no exercício de sua sexualidade ${ }^{4,5}$.

As relações afetivas íntimas entre jovens têm interface com os padrões sociais e culturais. Considera-se que os padrões tradicionais de gênero, arraigados por desigualdades sociais e sexuais, na maioria das vezes têm relevância para a manifestação da violência entre os sexos ${ }^{6}$.

A violência nas relações afetivas íntimas não é fenômeno recente e se constitui uma violação dos direitos humanos. Abrange parcela significativa da população mundial, considerada um problema de saúde desvalorizado e incompreendido. Acarreta prejuízos ao desenvolvimento físico, psicológico, reprodutivo, sexual, social e profissional, com implicações, ao longo do tempo, na saúde e bem-estar das pessoas envolvidas, podendo culminar em morte ${ }^{7,8}$.

Na maioria dos casos, a violência nas relações afetivas íntimas inicia-se nas relações com menor envolvimento, como o namoro. Perpetuando-se, com relativa probabilidade, na relação matrimonial estável ${ }^{9,10}$. Fator agravante nesse tipo de violência é que determinados atos de agressão, na relação afetiva íntima entre os jovens, não são percebidos como violência ou são mesmo banalizados, além de ações coercitivas e ciúme serem interpretados como demonstração de cuidado, atenção e amor ${ }^{11}$.

A violência nas relações afetivas íntimas entre jovens se insere em contextos de relações elaboradas culturalmente, influenciadas por modelos hegemônicos de gênero, que permeiam a reprodução da violência e a invisibilidade do fenômeno ${ }^{11,12}$.

Portanto, as ações de prevenção da violência interpessoal entre jovens, programas de intervenções e promoção da saúde, especificamente na violência no namoro, são imprescindíveis para estimular relações saudáveis e sem violência ${ }^{13}$.

\section{METOdOLOGIA}

Pesquisa qualitativa baseada na narrativa de vida como referencial teórico-metodológico na perspectiva etnossociológica proposta por Daniel Bertaux ${ }^{14}$.

O cenário do estudo foi uma universidade pública, localizada em um município do sudoeste da Bahia. Teve como participantes do estudo 30 jovens universitários do Curso de Graduação em Enfermagem. O curso é composto majoritariamente por mulheres, evidenciando a influência das questões de gênero nas relações afetivas íntimas. No intuito de garantir o anonimato dos participantes, foram identificados com a sigla PF (participante feminino) e PM (participante masculino), acompanhada dos números de 1 a 30, de acordo a sequência da entrevista, como por exemplo: PF1, PM2 e, assim, sucessivamente.

Foram utilizados como critérios de seleção dos participantes: discentes dos diversos períodos do Curso de Enfermagem, de 18 a 29 anos, que tivessem vivenciado uma relação afetiva íntima, independentemente do tempo de relacionamento. Os critérios de exclusão foram: jovens universitários que não frequentassem regularmente o curso, mesmo estando matriculados, e que apresentassem algum déficit de orientação espaço-temporal.

A coleta foi desenvolvida entre maio e setembro de 2017, após os estudantes aceitarem participar livremente da pesquisa e assinarem o Termo de Consentimento Livre e Esclarecido (TCLE). A pesquisa atendeu à Resolução no 466/2012, do Conselho Nacional de Saúde ${ }^{15}$. Trata-se de uma pesquisa que compõe um projeto maior intitulado Vulnerabilidade de jovens universitários à violência nas relações afetivas íntimas sob o olhar da enfermagem, aprovado 
pelo Comitê de Ética em Pesquisa da Faculdade Independente do Nordeste (CEP/FAINOR), parecer no 2.056.168 e CAAE 65091917.3.0000.8089.

A técnica de coleta das narrativas foi entrevista individual aberta, a partir de questão norteadora: Conte-me sobre suas relações afetivas íntimas. Ocorreu em local reservado na própria universidade, gravada, até atingir o ponto de saturação, que se estabelece como fenômeno por meio do qual o pesquisador compreende que não se obterá algo novo relacionado ao objeto de estudo, após determinado número de entrevistas ${ }^{14}$.

A partir das leituras exaustivas das narrativas e considerando a individualidade e a especificidade de cada participante, houve a síntese e agrupamento das unidades temáticas que deram origem à categoria - caracterização das relações afetivas íntimas de jovens universitários.

\section{RESULTADOS E DISCUSSÃO}

A idade dos participantes variou de 20 a 29 anos. Destes, 25 eram do sexo feminino e cinco do sexo masculino, caracterizando um curso eminentemente feminino. No que diz respeito à cor/etnia, sete participantes se declararam brancos, 18 pardos e cinco pretos, o que indica maioria de pessoas de etnia negra (23 participantes). Dos 30 participantes, 24 estavam se relacionando intimamente com alguém, em média de tempo de 2 semanas a 8 anos. Seis participantes afirmaram não estar se relacionando no momento.

\section{Caracterizando as relações afetivas íntimas de jovens universitários}

Em relação às características das relações afetivas íntimas, foi possível evidenciar que as participantes vivenciaram relacionamentos abusivos com parceiros ciumentos e controladores, pela proibição ou determinação do uso de roupas e pessoas com as quais poderiam manter amizade. Além da invasão da privacidade, com exigência da senha do celular ou de aplicativos de mensagens.

[...] ele era muito ciumento em relação à roupa, em relação a amigos. Eu cheguei até me afastar de umas pessoas, no começo, por conta dele. (PF 5)

Não tinha privacidade. Meu celular ele tinha a senha e eu nunca tive a senha dele, nunca permitiu que eu pegasse o celular dele. (PF 3)

Ele controlava o horário que eu entrava no WhatsApp. Eu não podia entrar no WhatsApp depois das 10 da noite, e não podia entrar antes das 8, porque ele tinha a ideia de que se eu estava on line nessa hora, falando com alguém. (PF 8)

[...] ele era insuportavelmente controlador. (PF 28)

Entre as diversas manifestações de controle, destaca-se recentemente o comportamento controlador por meio das redes sociais como o Facebook, Twitter, Instagram e WhatsApp, em que parceiras e parceiros inspecionam e acompanham constantemente a vida do outro como se fosse seu detentor. Há invasão de privacidade, motivada pela desconfiança e medo de estar sendo infiel, virtual ou realmente ${ }^{16-18}$.

O desejo de controlar o outro estaria associada ao sentimento de insegurança e ciúme, o qual, por vezes, na cultura ocidental, apresenta-se valorizado ao ser ressignificado como sinônimo de amor e cuidado ${ }^{19}$.

Nas narrativas, percebeu-se como notória a influência das questões de gênero e dominação masculina na forma como os parceiros das participantes determinavam como e com quem elas deveriam se relacionar, se comportar socialmente e o que deveriam ou não vestir, tratando-as como objetos. Ao mesmo tempo em que eles não permitiam ser controlados pelas parceiras.

Revelam as questões de desigualdade e violência de gênero e da existência de um patriarcado contemporâneo vigente, com alterações em sua configuração. Mas com a manutenção das premissas do pensamento patriarcal tradicional, o que implica a perpetuação do modelo das relações de autoridade e poder centradas no homem ${ }^{20}$.

Contraditoriamente, os jovens universitários do sexo masculino afirmaram que não eram ciumentos. As parceiras, sim, possuíam atitudes controladoras. Tais resultados corroboram o estudo realizado com adolescentes, no qual os rapazes ressaltaram que as moças faziam chantagem e pressões psicológicas, pressionando-os a permanecer no relacionamento ${ }^{21}$.

[...] não me importava que ela saísse, usasse tal tipo de roupa. Não tocava no celular dela, apesar dela pegar o meu. [...] ela tinha minha senha, eu não tinha a senha dela, ela via minhas coisas, eu não via as coisas dela, não tenho interesse, nunca fui ciumento. (PM 10)

[...] ela começou me controlar, mas eu nunca fui muito de controle [...] não chegou a ter nenhuma agressão. Eu nunca a agredi. Nunca fiz nada, muito pelo contrário, ela sempre reclamava que eu a deixava muito solta, porque também eu era solto, e eu não vou querer controlar ela. Mas, se ela quisesse uma coisa e eu não quisesse, já era muito mais complicado, eu tinha que fazer. [...] eu me sentia preso. (PM 15) 
As narrativas dos jovens masculinos revelaram que as mulheres são mais ciumentas do que os homens. Entretanto, nos discursos evidencia-se que homens e mulheres são ciumentos, sem desconsiderar as desigualdades de gênero estabelecidas culturalmente para o dito ciúme romântico, que associa a mulher como dependente emocionalmente do homem ${ }^{22}$.

O ciúme é indicado como um dos fatores que precipitam a ocorrência da violência entre namorados, segundo homens e mulheres ${ }^{2,23,24}$. A violência se legitima pautada em crenças apreendidas ao longo da vida, a partir do processo de socialização que desculpabiliza os comportamentos abusivos ${ }^{6}$.

Percebe-se nas narrativas dos jovens estudantes de enfermagem que existem elementos culturais arraigados, que tendem a favorecer a internalização de atos e atitudes controladoras no relacionamento afetivo entre jovens, naturalizando o ciúme.

Outro aspecto relevante é o fato de duas universitárias citarem o ciúme como algo saudável, visto como ato de proteção ou cuidado, demonstrando visão distorcida do sentimento.

Ele ligava pelo menos duas, três vezes ao dia para saber se eu estava em casa mesmo. [...] eu achava que era cuidado. (PF 11)

É um ciúme saudável, porque uma relação que não tiver ciúme, preocupação, não é uma relação verdadeira. É um ciúme saudável, porém, quando passa dos limites a gente percebe, conversa. (PF 29)

A compreensão do ciúme como sentimento positivo, que precisa estar presente nos relacionamentos, cuja ausência indicaria que a relação não estava bem, ampara-se no senso comum e fortes influências familiares. Apenas o excesso de ciúme indicaria um sinal de alerta ${ }^{25}$. Contudo, é difícil delimitar as atitudes como saudáveis, se há, na maioria das vezes, a invisibilidade na própria identificação da violência perpetrada e/ou vivida pelos jovens ${ }^{12}$.

Na mesma perspectiva de ciúme versus cuidado, algumas jovens assinalaram que não enxergavam o ciúme como manifestação de violência, ou demoraram a enxergá-lo. Mas conseguiram compreender após diálogos com amigos e/ou familiares que anotaram a existência de abusos nas relações. Uma das universitárias afirmou que só conseguiu perceber que estava vivenciando violência por parte do seu parceiro após participar das discussões em um grupo de pesquisa sobre violência de gênero, na universidade em que estuda.

Depois que eu comecei a participar do grupo de pesquisa de violência, comecei a me abrir e algumas vezes eu conversei com a professora. Ela disse: Você está vivendo [violência] todos os dias, já está violentada, já está oprimida [...]. Se liberte, seja você mesma. Aí eu comecei a parar para pensar em quem eu estava sendo, quem eu era. (PF3)

A narrativa reflete a importância de uma rede de suporte e apoio para ajudar a identificação dos abusos vivenciados nos relacionamentos afetivos, superá-los e estimular o estabelecimento de novos relacionamentos que tragam confiança e alegria. Geralmente, os amigos são as pessoas mais procuradas na busca de ajuda quando ocorre algum tipo de violência dentro do relacionamento amoroso. Em seguida os familiares, profissionais de saúde, religiosos e, por último, professores ${ }^{13}$.

[...] se eu tiver sofrendo alguma coisa, eu prefiro não compartilhar com ela, porque eu sei que pode querer resolver do jeito dela, mãe é mãe. (PF 12)

[...] não comentei nada com meus pais porque como virou um relacionamento de família, eu tinha medo de comentar, e lá na frente eu sofrer pelo término, e meu pai não deixar eu voltar com ele. (PF 30)

Observa-se nas narrativas das últimas participantes a dificuldade em dialogar com os pais sobre os relacionamentos. Geralmente há um controle excessivo dos familiares ${ }^{13}$. Jovens ocultam fatos que envolvem violência nos relacionamentos afetivos íntimos por medo, vergonha ou dificuldade de diálogo. Todavia, pais e familiares seriam importantes referenciais e suporte de apoio aos filhos. As relações interpessoais familiares deveriam ser estabelecidas pelo diálogo aberto e confiança.

\section{CONCLUSÃO}

Jovens estudantes do Curso de Graduação em Enfermagem estão expostos à vivência de distintas manifestações de violência nas relações afetivas íntimas. Basicamente, as questões sociais e de gênero influenciam diretamente a ocorrência das violências.

O Curso de Graduação em Enfermagem e outros da área da saúde devem atentar para o fenômeno da violência nas relações afetivas íntimas das graduandas e graduandos, na perspectiva da prevenção e enfrentamento das situações. E, ainda, como proposta de sensibilização dos jovens para as situações de violência presentes na sociedade, e que devem ser objeto futuro de cuidados com a população. 
Considerando o papel das universidades e sua importância na transformação da realidade social e qualidade de vida, e ainda na formação em saúde, destaca-se a urgência do desenvolvimento de ações preventivas e promoção de relacionamentos saudáveis entre jovens universitários.

O presente estudo foi limitado porque se concentrou apenas em uma universidade e em um curso de graduação. Todavia, o artigo reflete uma realidade local de ampla magnitude, com vistas a contribuir para a realização de novos estudos.

\section{REFERÊNCIAS}

1. Pereira AB. Juventude, juventudes. Revista Teoria e debate [Internet]. 2012 [cited 2019 Jan 05]; 99(4). Available from: https://teoriaedebate.org.br/2012/04/12/juventude-juventudes/

2. Caridade S. Vivências íntimas violentas: uma abordagem científica. Coimbra (Pt): Almedina; 2011.

3. Cornelius TL, Bell KM, Wyngarden N, Shorey RC. What happens after I hit? A qualitative analysis of the consequences of dating violence for female perpetrators. Violence and Victims. 2015 [cited 2019 Jan 05]; 30(3):393-16. DOI: https://doi.org/10.1891/0886-6708.VV-D-13-00058

4. Novella R, Repetto A, Robino C, Rucc G. Millennials na América Latina e no Caribe: trabalhar ou estudar? Washington (DC): Banco Interamericano de Desenvolvimento; 2018 [[cited 2019 Feb 05];]. Disponível em: http://dx.doi.org/10.18235/0001411

5. Ministério da Saúde (Br). Secretaria de Atenção à Saúde. Departamento de Ações Programáticas Estratégicas. Marco teórico e referencial: saúde sexual e saúde reprodutiva de adolescentes e jovens. Brasília (DF): Ministério da Saúde; 2007.

6. Antunes $\mathrm{O}$. Violência nos relacionamentos íntimos em estudantes universitários [dissertação de mestrado]. Lisboa (Pt): Universidade Lusófona de Humanidade e Tecnologias; 2016. [cited 2019 Jan 05]; Available from: http://recil.ulusofona.pt/bitstream/handle/10437/7152/Viol\%C3\%AAncia\%20nos\%20relacionamentos\%20\%C3\%ADntimos.pdf? sequence $=1$

7. World Health Organization. Estudo multipaís da OMS sobre a saúde da mulher e da violência doméstica contra a mulher. Geneva (Swi): WHO; 2005.

8. World Health Organization. United Nations Programme on HIV/AIDS. Addressing violence against women and HIV/Aids: What works? Geneva (Swi): WHO; 2010.

9. Santos JCSM. Violência no namoro: concepções e percepções dos jovens em função do género. [dissertação de mestrado]. Coimbra (Pt): Escola Superior do Curso de Enfermagem; 2014. [citado em 20 jan 2019]. Available from: http://repositorio.esenfc.pt/?url=zjLQptXf

10. Flake TA, Barros C, Schraiber LB, Menezes PR. Intimate partner violence among undergraduate students of two universities of the state of São Paulo, Brazil. Rev Bras Epidemiol [Internet] .2013 [cited 2019 Jan 05]; 16(4):801-16. DOI: http://dx.doi.org/10.1590/S1415-790X2013000400001

11. Nascimento FS, Cordeiro RLM. Violência no namoro para jovens moradores de Recife. Psicologia \& Sociedade. 2011 [cited 2019 Jan 05]; 23(3):516-25. Available from: http://www.scielo.br/pdf/psoc/v23n3/09.pdf

12. Gomes R. Invisibilidade da violência nas relações afetivo-sexuais. In: Minayo MCS, Assis SG, Njaine K, organizadores. Amor e violência: um paradoxo das relações de namoro e do "ficar" entre jovens brasileiros. Rio de Janeiro: Fiocruz; 2011, p. 141-51.

13. Njaine K, Oliveira QBM, Ribeiro FML, Minayo MCS, Bodstein R. Prevenção da violência nas relações afetivo-sexuais. In: Minayo MCS, Assis SG, Njaine K. organizadores. Amor e violência: um paradoxo das relações de namoro e do "ficar" entre jovens brasileiros. Rio de Janeiro: Fiocruz; 2011. p. 183-205.

14. Bertaux D. Narrativas de vida: a pesquisa e seus métodos. Tradução de Zuleide Alves Cardoso Cavalcante e Denise Maria Gurgel Lavallée. 2a ed. São Paulo: Paulus; 2010.

15. Ministério da Saúde (Br). Conselho Nacional de Saúde. Resolução no 466, de 12 de dezembro de 2012. [cited 2019 Jan 05]. Available from: http://bvsms.saude.gov.br

16. Silva CYG. O ciúme nas relações amorosas adolescentes. In: Almeida T, organizador. Relacionamentos amorosos: 0 antes, o durante e o depois. Vol. 2. São Paulo: PoloBooks. 2014, p. 133-57.

17. Santos C, Melo M. Ciúme nas relações amorosas de adolescentes: questões de género e orientação sexual. In: Pereira $A$, Calheiros M, Vagos P, Direito I, Monteiro S, Fernandes CS, Gomes AA, organizadores. 70 Simpósio Nacional de Investigação em Psicologia; 2013; Aveiro (Pt): Associação Portuguesa de Psicologia; 2013. p. 247-56 [cited 2019 Jan 05]. Available from: https://dspace.uevora.pt/rdpc/handle/10174/10133

18. Morais C. O amor e o facebook: como a maior rede social do mundo pode influenciar a sua vida emocional. Lisboa (Pt): Oficina do Livro; 2011.

19. Almeida T, Lourenço ML. Ciúme romântico: um breve histórico, perspectivas, concepções correlatadas e seus desdobramentos para os relacionamentos amorosos. Revista de Psicologia. 2011 [cited 2019 Jan 05]; 2(2): 18-32. Available from: http://www.periodicos.ufc.br/psicologiaufc/article/view/87/86

20. Fávero MH. Psicologia do gênero: psicobiografia, sociocultura e transformações. Curitiba (PR): Editora UFPR; 2010.

21. 21.Oliveira QBM, Assis SG, Njaine K, Oliveira RVC. Violência nas relações afetivo-sexuais. In: Minayo MCS, Assis SG, Njaine K, organizadores. Amor e violência: um paradoxo das relações de namoro e do "ficar" entre jovens brasileiros. Rio de Janeiro: Fiocruz; 2011. p. 87-140.

22. Carvalho LF, Ambiel RAM. Sex Differences in romantic jealousy: a Brazilian study. Avances en Psicología Latinoamericana [Internet]. 2016 [citado em 06 jan 2019]; 34(1):143-55. DOI: http://dx.doi.org/10.12804/apl34.1.2016.10 
23. Monteiro, ASC. Avaliar atitudes para prevenir comportamentos: As atitudes dos jovens universitários acerca da violência no namoro [dissertação de mestrado]. Porto (Pt): Universidade do Porto; 2015. [citado em 06 jan 2019]. Available from: https://sigarra.up.pt/icbas/pt/pub_geral.pub_view?pi_pub_base_id=120463

24. Leisring PA. Physical and emotional abuse in romantic relationships motivation for perpetration among college women. Journal of interpersonal violence [Internet] 2013 [cited 2019 Jan 05]; 28:1437-54. DOI: https://doi.org/10.1177/0886260512468236

25. Turatti MC, Lucas MG. Compreendendo o ciúme na relação conjugal: um olhar sistêmico. Unoesc \& Ciência - ACBS [Internet]. 2016 [cited 2019 Jan 05]; 7(2):145-52. Available from: https://portalperiodicos.unoesc.edu.br/acbs/article/view/11945 